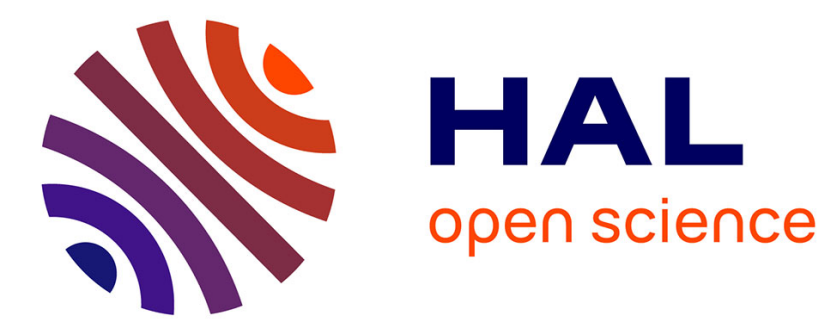

\title{
GROWTH KINETICS OF ICOSAHEDRAL PARTICLES IN GOLD FILMS CONDENSED ON NaCl SUBSTRATE
}

\author{
M. Gillet, A. Renou
}

\section{> To cite this version:}

M. Gillet, A. Renou. GROWTH KINETICS OF ICOSAHEDRAL PARTICLES IN GOLD FILMS CONDENSED ON NaCl SUBSTRATE. Journal de Physique Colloques, 1977, 38 (C2), pp.C2-211C2-213. 10.1051/jphyscol:1977244 . jpa-00217084

\section{HAL Id: jpa-00217084 https://hal.science/jpa-00217084}

Submitted on 1 Jan 1977

HAL is a multi-disciplinary open access archive for the deposit and dissemination of scientific research documents, whether they are published or not. The documents may come from teaching and research institutions in France or abroad, or from public or private research centers.
L'archive ouverte pluridisciplinaire HAL, est destinée au dépôt et à la diffusion de documents scientifiques de niveau recherche, publiés ou non, émanant des établissements d'enseignement et de recherche français ou étrangers, des laboratoires publics ou privés. 


\title{
GROWTH KINETICS OF ICOSAHEDRAL PARTICLES IN GOLD FILMS CONDENSED ON NaCI SUBSTRATE
}

\author{
M. GILLET and A. RENOU \\ Laboratoire de Microscopie et Diffraction Electroniques (*), \\ Faculté des Sciences et Techniques de Saint-Jérôme, 13397 Marseille cedex 4, France
}

\begin{abstract}
Résumé. - Les films d'or condensés sur les halogénures alcalins présentent dans certaines conditions expérimentales des particules de structure icosaédrique en proportion relativement élevée et avec une taille moyenne supérieure à celle des particules de structure c.f.c. Dans un premier stade de croissance, nous supposons qu'il se forme des particules icosaédriques et des particules c.f.c. et que dans les conditions de forte sursaturation la cinétique de croissance conditionne la structure finale. Avec un mécanisme de croissance couche par couche, nous déterminons la cinétique de croissance des particules icosaédriques et c.f.c. Nous montrons que la croissance des particules icosaédriques est favorisée par rapport à celle des particules c.f.c., ce qui est conforme à l'expérience.
\end{abstract}

Abstract. - Gold particles condensed on alkali halides have sometimes icosahedral structure. Particles with icosahedral structure appear in certain experimental conditions with a relative high frequency and their mean size is often greater than the one of c.f.c. particles. In a first stage of growth we suppose that icosahedral and c.f.c. particles nucleate and in the conditions of high supersaturation the final structures are determined by growth kinetics. With a layer by layer growth mechanism we calculate the growth kinetics of icosahedral and c.f.c. particles. It is shown that icosahedral particles growth is favoured compared to the c.f.c. one, in good agreement with experimental results.

Since some years a relatively large number of theoretical and experimental works was consacreted to the atomic structure of small particles formed in the first stages of solid phases growth [1-7] and [8-16]. It is found that these small clusters within a size range from some atoms to some thousand atoms, are often characterized by fivefold symmetry axes. Then, particles which grow have often bipyramid pentagonal or icosahedral structures. It is obvious that on the one hand in most cases where such particles were observed, the growth is not except perhaps in the first stages a thermodynamic equilibrium phenomena. On the other hand, when such structures growth is possible, they are favoured with respect to normal ones. In this paper, we show that the growth of gold particles which exhibit fivefold symmetry axes and pentagonal or icosahedral shapes is in some experimental conditions favoured with respect to growth of c.f.c. structure and usual shapes.

1. Layer by layer growth mechanism. - We shall suppose that, in a first stage, we have the same number of icosahedral and normal particles. Icosahedral particles are limited by triangular faces in which the stacking of atoms is nearly the same, that in (111) face of c.f.c. structure. Normal c.f.c. particles are limited by (111), (110) or (100) dense faces. We suppose that the two kinds of particles

(*) Associé au C.N.R.S. ERA $n^{\circ} 545$. have no dislocation which should lead to spiral growth mechanism. Then the growth occurs layer by layer from a two-dimensional nucleus which appears on a face of the particle and grows atom by atom.

So we distinct two stages in the formation of a layer on a face : first the two-dimensional stable nucleus formation which occurs during $T_{\mathrm{N}}$ (nucleation time) and secondly the formation of the layer by lateral extension of the two-dimensional nucleus (atom by atom process). This second stage occuring during $T_{\mathrm{c}}$ (growth time) we shall suppose that the stable nucleus is formed by a pair of adsorbed atoms on the face of the particle so an atom from the vapour phase will incorporate with this nucleus if, at least, it is bound to five nearest neighbours. We have shown elsewhere [17] that if the growth proceeds by a two-dimensional mechanism, the formation of a stable nucleus on a face of icosahedral particle leads to the formation of a complete shell on all the free faces of the particle whereas in the case of c.f.c. particle, limited by (111) (110) (100) dense faces, the formation of a stable nucleus leads to the growth of a layer only on the face which contains the nucleus.

2. Growth kinetics of icosahedral and c.f.c. particle. - Initially we suppose the formation of two kinds of particles : icosahedral and c.f.c. particles. Icosahedral particles often have the shape of a half icosahedron cut by the plane of the substrate which 
contains the center of the icosahedron and lies parallel to an edge of the icosahedron [16]. We compare the growth kinetics of these icosahedral particles to the growth kinetics of c.f.c. : particles, which have a squared base pyramidal shape with a (001) plane parallel to the substrate plane and limited by four (111) faces. Initially the two kinds of particles have approximately the same size.

2.1 FORMATION AND GROWTH OF A TWODIMENSIONAL NUCLEUS ON A FACE OF A PARTICLE. - If a crystal face is exposed to an atomic flux $F$ from the vapour phase, the concentration of adsorbed atoms on this face if we assume an equilibrium between the impingent flux and the desorbed flux is $n_{1}=F \tau(\tau$ : residence time of an atom on the surface of the substrate). During heterogeneous nucleation at high supersaturation we suppose the critical nucleus composed of a single atom the stable nucleus is defined as containing one atom more than the critical nucleus so that the nucleation rate is calculated as the rate of formation of the stable nuclei that is the rate of formation of a pair of atoms.

According to Walton [18] the capture of an single atom by a critical nucleus gives stable nucleus which can grow spontaneously. We can write the frequency $\Gamma$ with which an adsorbed atom can impinge the critical nucleus by surface diffusion as a function of the size $i$ of the critical nucleus [17] :

$$
\Gamma=2 \pi^{1 / 2} i^{1 / 2} \overline{F \bar{X}^{2}}
$$

$i$ : number of atoms contained in the critical nucleus, $\overline{X^{2}}$ : average quadratic distance of superficial diffusion. As the critical nucleus contains only one atom $(i=1)$ nucleation rate on a particle face is :

$$
I=n_{1} \Gamma=2 \pi^{1 / 2} F^{2} \tau \bar{X}^{2}
$$

So the nucleation time on a face with a surface area $S$ is :

$$
T_{\mathrm{N}}=(I . S)^{-1} \text {. }
$$

When the stable nucleus is formed, the capture rate of atoms by a nucleus is proportional to $\Gamma$ and the growth time for the formation of a complete layer on the face by an atom by atom process is :

$$
T_{\mathrm{c}}=\frac{s^{1 / 2} / a-2}{\pi^{1 / 2} \overline{F X}^{2}} .
$$

With experimental conditions defined by $F=10^{14}$ at $/ \mathrm{cm}^{2} / \mathrm{s}, \quad \tau=2.3 \times 10^{-5} \mathrm{~s}, \overline{X^{2}}=3 \times 10^{-11} \mathrm{~cm}^{2}$ and $T=300^{\circ} \mathrm{C}$ and if $S=10^{3} \AA^{2}$, then $T_{\mathrm{N}}=4 \times 10^{-1} \mathrm{~s}$, $T_{\mathrm{c}}=1.7 \times 10^{-2} \mathrm{~s}$. So $T_{\mathrm{c}} \ll T_{\mathrm{N}}$ means we have two distinct and successive stages for a layer growth. We shall consider only this simple case where no renucleation exists before the growing of the layer is complete. This is performed for cap-shaped particles with a radius lower than $80 \AA$.
2.2 GROWTH KINETICS OF AN ICOSAHEDRAL PARTICLE. - We shall consider an icosahedral particle with $P$ free faces of surface $S$. We know that one two-dimensional nucleus is sufficient to generate a complete layer on the $\boldsymbol{P}$ faces. The time required for the formation of a complete shell is :

$$
T_{i}=T_{\mathrm{N} i}+T_{\mathrm{ci}}=(I P S)^{-1}+\frac{(P S)^{1 / 2} / a-1}{\pi^{1 / 2} \overline{F X}^{2}} .
$$

We can consider the particle as half a sphere with radius $R$. If the thickness of a complete layer on every free face of the particle is $a$ the growth rate at the time $t$ can be expressed by $: \frac{\mathrm{d} R}{\mathrm{~d} t}=\frac{a}{T_{3}}$ with :

$$
T_{i}=\frac{1}{2 \pi^{1 / 2} F^{2} \bar{X}^{2} \tau P S}+\frac{(P S)^{1 / 2} / a-1}{\pi^{1 / 2} \overline{F X}^{2}}
$$

$\operatorname{As}(P S)^{1 / 2} / a \gg 1$ and with :

$$
\begin{gathered}
K_{1}=\frac{1}{4 \pi^{3 / 2} F^{2} \bar{X}^{2} \tau} \text { and } K_{2}=\frac{2^{1 / 2}}{F \bar{X}^{2} a} \\
\frac{\mathrm{d} R}{\mathrm{~d} t}=\frac{a R^{2}}{K_{1}+K_{2} R^{3}} .
\end{gathered}
$$

We obtain by integration

$$
t=\frac{K_{1}}{a}\left(\frac{1}{R_{0}}-\frac{1}{R}\right)+\frac{K_{2}}{2 a}\left(R^{2}-R_{0}^{2}\right)
$$

where $R_{0}$ is the radius of the initial icosahedral particle. This equation gives the growth kinetics of icosahedral particle. So we have plotted figure 1 (full line curves) the size of the particle (Number $N$ of atoms in the particle of radius $R$ ) versus time $t$ for two different values of the impinging flux $\left(F=10^{14}\right.$ and $2 \times 10^{14}$ atoms $\left./ \mathrm{cm}^{2} / \mathrm{s}\right)$ and a substrate temperature of $300^{\circ} \mathrm{C}$. Initial time $t=0$ is the time from which we consider the growth of the particle with a radius $R_{0}=10 \AA$.

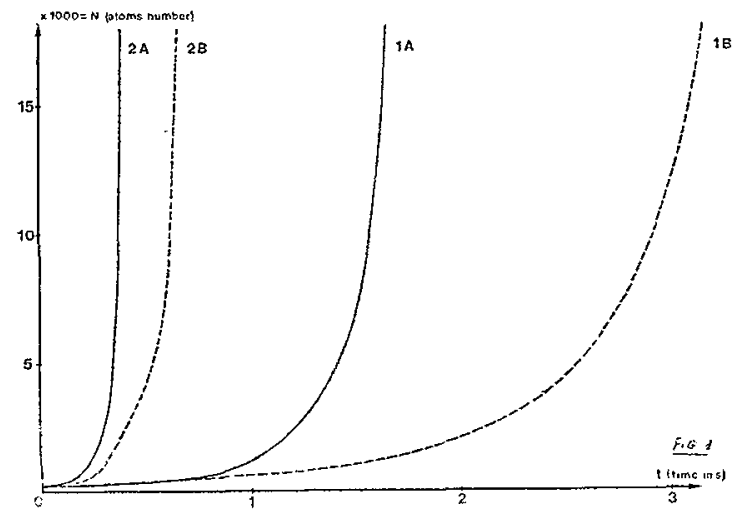

FIG. 1. - Growth kinetics of icosahedral particles : Full line curves $1 \mathrm{~A}$ and $2 \mathrm{~A}$ corresponding to impinging flux of $F=10^{14}$ and $F=2 \times 10^{14}$ atoms $/ \mathrm{cm}^{2} / \mathrm{s}$.

Growth kinetics of f.c.c. particles : dotted line curves $1 \mathrm{~B}$ and $2 \mathrm{~B}$ corresponding to impinging flux of $F=10^{14}$ and $F=2 \times 10^{14}$ atoms $/ \mathrm{cm}^{2} / \mathrm{s}$.

2.3 GROWTH KINETICS OF A C.F.C. PARTICLE. We consider a particle with c.f.c. structure, a 
squared base pyramidal shape and faces limited by (111) planes. From an energetic point of view, these planes are similar to those limiting the icosahedral particle. In the case of the two-dimensional nucleus growth process that we have considered, the formation of a stable nucleus on a face (111) gives rise to a layer only on a face (111) so it will be required that a renucleation takes place on every face to realize a complete shell on all the free faces of the pyramid and the time of formation of this shell will be :

$$
t=T_{\mathrm{Np}}+T_{\mathrm{cp}}
$$

where $T_{\mathrm{Np}}$ is the nucleation time of a nucleus on a free face of the pyramid and $T_{\mathrm{cp}}$ is the growth time of a layer on this face. In that case, it is required to compute the time $t$ layer by layer

$$
t=\frac{N_{0}}{2 \pi^{1 / 2} F^{2} \bar{X}^{2} \cdot \tau n_{\mathrm{f}}}+\frac{\left(n_{\mathrm{f}}\right)^{1 / 2}-1}{\pi^{1 / 2} \overline{F X^{2}}}
$$

$n_{\mathrm{f}}=$ number of atoms on the (111) considered face of the gold particle, $N_{0}=$ number of atoms by $\mathrm{cm}^{2}$ on a (111) face.

Initial particle contains 285 atoms (icosahedral particle contains 250). We have plotted figure 1 (dotted line curves) the growth kinetics that is to say the number of atoms $N$ of the particle versus time $t$ for two values of the impinging flux $\left(F=10^{14}\right.$ and $2 \times 10^{14}$ atoms $/ \mathrm{cm}^{2} / \mathrm{s}$ ) and a substrate temperature of $300^{\circ} \mathrm{C}$.

The results show that in the first stages of the formation of gold particle and with given experimental conditions, the growth rate of icosahedral particles is higher than c.f.c. One. If during the nucleation stage or during the first growth stages there is formation of the same number of icosahedral and c.f.c. particles limited by dense faces, the growth of icosahedral particles will be favoured, so icosahedral particles will be much numerous than c.f.c. ones and will have a greater size. This fact is due to particle shape which allows in a growth process by two-dimensional nucleus, the growth of a complete shell on all free faces from only one stable nucleus formed on any face.

\section{References}

[1] Burton, J. J., J. Chem. Phys. 52 (1970) 345

[2] BURTON, J. J., Nature 229 (1971) 335.

[3] Hoare, M. R., Pal, P., Nature 230 (1971) 5.

[4] Hoare, M. R., Pal, P., Adv. Phys. 20 (1971) 161.

[5] HoAre, M. R., PAL, P., Nature 236 (1972) 35.

[6] Hoare, M. R., Pal, P., J. Cryst. Growth 17 (1972) 77.

[7] Bonnissent, A., Mutaftschiev, B., J. Chem. Phys. 58 (1973) 3727

[8] Kimoto, K., Nishida, I., J. Phys. Soc. Japan 22 (1967) 940.

[9] Ino, S., J. Phys. Soc. Japan 21 (1966) 346.

[10].Ino, S., OGawa, S., J. Phys. Soc. Japan 22 (1967) 1365.
[11] Gillet, E., Gillet, M., J. Cryst. Growth 13 (1972) 212 ; Bull. Soc. Fr. Minéral Cristallogr. XC (1965) 54.

[12] Scrwoebel, R. L., J. Appl. Phys. 37 (1966) 2515.

[13] Allpress, J. G., Sanders, J. V., Surf. Sci. 7 (1965) 1.

[14] Yagl, K., TakaYanaGi, K., KobaYashi, K., HonJo, G., $J$. Cryst. Growth 28 (1975) 117.

[15] Darby, T. P., Wayman, C. M., J. Cryst. Growth 28 (1975) 41

[16] Gillet, E., Gillet, M., Thin Solid Films 15 (1973) 249.

[17] Gillex, M., J. Cryst. Growth (à paraître).

[18] Walton, D., J. Chem. Phys. 37 (1962) 2182. 